\title{
Da loucura das imagens à imagem daloucura'
}

A EXPANSĀO DO CAPITAL - primeiro lenta e restrita, depois acelerada e mundial; vale dizer: antes, material e simbólica e, hoje, também imaginária - tem, mais ainda nas últimas décadas, se ancorado no maciço investimento em descobertas tecnológicas e em ciências de ponta (engenharia microeletrônica e informática, física e genética). Os resultados das pesquisas desenvolvidas nesses campos do conhecimento foram, e constantementesão, apropriados pela política, socializando-se para além dos sofisticados laboratórios e forçando, assim, a vida social a se organizar em novas bases.

Foram, porém, a engenharia microeletrônica e a computação que produziram impacto mais substancial na vida cotidiana, alterando profundamente o sistema de parâmetros sociais norteadores da ação individual e coletiva. Essas duas áreas vigoram como as bases infra-estruturais da geração espiral e circulação veloz de informaçōese imagens. Compõem um campo específico de trabalho profissional, ultraespecializado e avançado, cuja operação permanente cria, fundamenta e assegura não só um novo tipo de vida cotidiana, mas sobretudo um outro imaginário social. Tornou-se arcaico o argumento de que os equipamentos delas provenientes permitem fluxos de comunicaşāo no interior da sociedade; tais máquinas comunicacionais são, na verdade, os avatares da própria sociedade da comunicação, ${ }^{3}$ caracterizada pela produção e reproduçāo de informaçōese imagensnão como meio objetivo de estimular a formação e a racionalidade da opinião pública, como nos séculos XVIII e XIX, mas como fim em si mesmo. Nesse aspecto, a massa de informações e imagens é dirigida ao imaginário de indivíduos isolados, permanecendo nestes limites suas repercussões. $\mathrm{Na}$ 
sociedade da comunicaçāo, as informaçōes e imagens não trazem no bojo normas ou parâmetros para a ação e para a estrutura psíquica, como se fossem puras formas que meramente transmitem conteúdos sociais e culturais consolidados. Tal fasejá foi superada. $\mathrm{Na}$ atualidade, elas, proliferando em circuito vertiginoso e refratadas ao infinito, como num jogo de espelhos, transformaram-se nas próprias normas ou parâmetros para a vida cotidiana privada e pública. Este é o aspecto predominante de seu movimento: não reproduzem, em cópias, os norteadores da vivência; elas o são. Esse acontecimento, de extrema importância, tem grandes implicações para esobre a realidade. Culturalmente falando, é um outro mundo que se põe e se move diante de nossos olhos e ao arrepio dos conceitos teóricos vigentes, por demais viciados e envelhecidos para compreendê-lo. Basta lembrar, de partida, que, na sociedade da comunicação, não prevalece a ética, antes garantida por normas fixadas pela tradição, mas a estética, financiada pela circulação pura e incessante de fluxos programáticos, imagéticos e informativos. Enquanto à ética correspondia a ação norteada pela tradição e pela modernidade, à estética corresponde a performance determinada por modelos proliferados.

\section{II}

Nesse universo estético, aleatório e movente são as imagens que, obviamente, adquirem especial relevo.

A história das imagens em relação ao seu referente, vale dizer, à realidade, ainda está para ser melhor escrita. Por oportuno, indiquem-se aqui, muito a grosso modo, as fases desse processo, seguindo uma lacônica pista sugerida por Baudrillard. ${ }^{4}$ Houve um tempo em que as imagens foram, predominantemente, um reflexo de uma realidade profunda. Tratava-se de uma boa aparência, materializada, para aquilo que se concebia no imaginário individual e social (as formas de uma divindade, o rosto de um santo, etc.). Em seguida, em contraponto a essa primeira fase, as imagens foram consideradas máscaras de uma realidade profunda. No caso, elas deixaram deser uma aparência estética precisa (mero reflexo) de um objeto que, embora presente somente no imaginário, alcançável apenas pela intuição e não pelos sentidos físicos, era considerado como real. Depois, sucede outra fase, na qual a imagem arriscase a uma aparência de algo que não existe de fato como realidade, istoé, mascara a ausência de uma realidade profunda. Trata-se de uma criação aleatória, cuja credibilidade de massa, legitimidade e veracidade se sustentam sob o pretexto de que a realidade-referente das imagens permanece ainda presente; em outras palavras, sob a ilusão da presença (enquanto realidade) do referente das imagens. ${ }^{5}$ Por fim, numa fase mais avançada, a do presente, as imagens circulam sem dar nenhuma satisfação aos seus referentes; ou melhor, perdem os referentes e passam a não se relacionar mais com realidade alguma. ${ }^{6}$ Enlouquecimento da lógica do signo imagético: a separação sem apelos entre signo e referente gera uma crise no relacionamento entre significante e significado; disso resulta a cisão entre tais dimensões, a partir da qual o significante (a imagem pura, nocaso) ganha autonomia absoluta e predomina em bloco sobre o significado. Tem-se, pois, a fragmentação completa do signo imagético.

O mundo atual é o das imagens sem sentido, sem origem, sem rumo e sem fronteiras. Circulam e se reciclam vertiginosamente, sem cessar, enlouquecidas quanto ao motivo antropológico e cultural de sua existência. Invadem todos os domínios culturais, percorrem todos os caminhos possiveis, no limite do "circuito integrado" em que se converteu o sistema sociocultural depois da emergência e desenvolvimento dos media infoeletrônicos e dos satélites de comunicação; preenchem todos os espaços, todos os canais de percepção sensorial, projetam-se, de modo veemente, sobre o imaginário individual, reproduzindo-se e refratando-se aceleradamente a partir de si 
próprias.

A base material de sustentaçăo desse fenômeno săo, como sugerido antes, as técnicas de reprodução altamente sofisticadas e toda a parafernália eletrónica de difusãoem massa espalhada pelo social, nas ruas, nas casas, nas empresas, nos clubes, abrangendo um número cada vez menor de pessoas por equipamento individual?

A produçào, circulação e reprodução das imagens (aliás, imagem de tudo, inclusive do que outrora era impensável, como a dos seres vivos nas profundezas do oceano, a do interior do corpo humano e do cotidiano de astronautas na estação espacial) transformaram, pois, o panorama sociocultural da sociedade tecnológica atual. É como se, no transcorrer das duas últimas décadas, as imagens tivessem assumido total preponderância em relaçăo a tudo o que pertence à dimensão cultural. Tudo se torna imagem, tudo possui (ou deve possuir) uma imagem, tudo precisa se transformar em imagem. Tal fato é, aparentemente, banal e suas implicações teóricas e práticas para a vivência cotidiana poderiam passar despercebidas, não fossem, com efeito, sérias."

Afirmou-se antes que as imagens, em sua fase atual e avançada, nenhuma relaçăo guardam com a realidade. Contudo, se circulam sem esse liame e se predominam na cultura, nem por isso deixam de remeter a alguma coisa. Tal é o detalhe: remetem a elas mesmas. Em rede, independentizaram-se do referente para se tornarem auto-referentes, configurando um estranhocirculo viciosoque só atesta o seu delírio. Vigoram como o seu próprio referente e seu próprio horizonte. Perderamovínculocom a realidadeordinária herdada apenas para se assumirem, paulatinamente, como realidade perante e para si mesmas, bem como diante de todos; fazem as vezes do real, passam-se por ele, são hoje " $\mathrm{a}^{\prime \prime}$ realidade referencial para a ação individual $e$ coletiva. Converteram-se em nosso maior objeto de investimento libidinal e visual. Essa assunção da realidade por parte da rede de imagens marca uma transferencia radical de polaridade: o que antes era papel do real, encarado em seu sentido tradicional (como esfera dos objetos, mercadorias, corpos, processos, etc., em sua suposta unicidade imediata), passa agora, por uma proeza do desenvolvimento tecnologico avançado, aser desempenhado pelo "duplo" dessa mesma realidade. Do ponto de vista da estrutura psíquica e do comportamento individual e de massa, tal substituição aponta para uma desreferencializaçăo seguida de uma nova referencialização. Movimento que revela a potência mortifera das imagens': superando o real e absorvendo o seu papel social, elas o estiolam até matá-lo para, enfim, ocupar o seu trono. Ao fim deste processo, inauguram uma atmosfera cultural inteiramente outra, que, com certeza, não se pode chamar de "realidade", nem de "real". Com Baudrillard, pode-se nomeá-la de hiper-real, ${ }^{20}$ quer dizer, algo mais real que o real, tão real que, paradoxalmente, deixa de sê-lo. Năoobstante, a rede de imagens socialmente existente se apresenta como realidade mesma, como se nada tivesse mudado. Reside aí a simulação, segundo Baudrillard. Dissimular é fingir que não existe o que de fato existe; simular, ao contrário, é fingir que existe o que já deixou de existir." Nessa perspectiva, as imagens fingem ser, socioculturalmente, a realidade queelas mesmas implodiram; simulamexistir ainda o que ja desapareceu, dando lugar a outro processo, a outro fenômeno.

A predominância das imagens no social realça e sedimenta o componente estético da cultura, conferindo-lhe liberdade infinita. $\mathrm{O}$ panorama hiper-real é, para o que interessa neste artigo, o da estetização geral dos ambientes, ruas e praças, corpos e cabeças, produtos e discursos. ${ }^{12}$ Tudo vale no valetudo estético. O processo de estetização, que tudo varre e reconfigura na sociedade tecnológica contemporânea, está submetido a um eixoestrutural semelhante ao da moda ${ }^{13}$ - estrutura na qual o que já foi tem sempre chance de voltar em forma de novidade comercial, em vista do livre remanejamento de elementos já criados e recriados. Por isso, a única regra da estética atual é a do desregramento, embora esta tenha que se 
realizar nos marcos do gosto de época, mediado pela indústria da cultura e, por isso, sempre sujeito a reciclagens infindas. Do ponto de vista antropológico, tal é a etapa por que passam, sem escapatória, os homens: doravante, precisam se socializar num universo cada vez mais estetizado, articulado e modulado por tecnologias eletrônicas comunicacionais.

\section{III}

Num famosoestudosobre ocaráter ea cultura americanos, Riesman criou três conceitos para elucidar e diferenciar três padrões de individuo existentes até a década de 60 nos Estados Unidos. ${ }^{14}$ Esses conceitos são a traditivo-direção, a introdireção e a alterdireção. No primeiro caso, enquadram-se individuos cujo comportamento é norteado pela tradição (história objetivada, sedimentada, em sua forma prático-moral-religiosa); no segundo caso, aparecem indivíduos cujo comportamento é balizado por seu próprio interior, seus desejos, sentimentos e ideais; $e$, no terceiro, tem-se individuos cujo comportamento é modulado pelo comportamento dosdemais. Reescalonadaaonivel da história, essa perspectiva teórica remete a fases socioculturais com as características acima apontadas eque, segundo Riesman, sucedemse no tempo na mesma ordem: a fase em que a vida coletiva era dirigida pela tradição cede lugar à fase em que vigora a introdireção, que, por sua vez, é superada pela fase em que o comportamento alheio prepondera na hierarquia de valores sociais, caracterizando a alterdireção. Embora versando sobre a natureza do caráter e da cultura de um povo especifico, o estudo - apesar de muito criticado, bastante esclarecedor - poderia ser estendido para além das fronteiras que o validam e seus conceitos, utilizados para elucidar objetos em outros lugares do mundo atual. Seria necessário, no entanto, uma atualização dos dados da obra, até mesmo-e, talvez, principalmente - para se adequar ao momento presente da cultura norte-americana, pois, se o tipo de vida alterdirigido, havido nos Estados Unidos nas décadas de 50 e 60 , foi exportado e podia ser percebido em diferentes paises, ele já foi por demais ultrapassado. A vida social que se processa nos marcos das fronteiras nacionais misturase a uina cultura internacionalizada - que remete ao que se pode denominar o cultural mundializado, modelo de cultura que circula em espiral numa época tecida por redes comunicacionais. E este cultural mundial, marcado por imagens, aponta para outra fase, outro tipo de vida, que seria, na esteira dos conceitos de Riesman e na perspectiva deste artigo, o tipo de vida imagético-dirigido. Nele, tem-se massas de individuos cujo comportamento é norteado pelas imagens tecnosocialmente difundidas. Aqui, o outro e seu comportamento deixam de ter primazia na vida social e desaparecem de cena.

\section{$\mathbf{N}$}

Nesse contexto, a socialização é um processo ainda mais complexo. A circulação pura, acelerada e incessante de fluxos imagéticos produz - como não poderia deixar de ser remanejamentos internos na estrutura psíquica e a convida (diria, incita, tantos que são os estímulos e pressôes cotidianos) a funcionar em novas bases. O ego, estruturalmente enfraquecido como organizador psíquico, tem sua função inconsciente despertada, enquanto a consciente se estiola por falta de incentivo social. Com isso, o imaginário, tecido pelo exercício da função inconsciente do ego, sobrepõe-se à racionalidade, produto exclusivo do exercício da função consciente do mesmo. Em outros termos, a operação imaginária do ego, agora sem limites, adquire hegemonia no interior da estrutura psíquica, em prejuizo de sua operação racional, bastante limitada $e$ desguarnecida numa sociedade estruturada 
para fomentar o imaginário. Por sua vez, o superego, instância de censura e auxiliar do recalque, fica sem função definida e perde seu sentidooriginal. E, por suposto, oinconsciente ganha novos direitos na estrutura psiquica e novos horizontes na cultura. Desejos, fantasias e pulsões se liberam e são instigados frequientemente. Diante disso, poder-se-ia dizer que não se trata bem de meros remanejamentos internos, mas de uma verdadeira implosão, se se tomar como referência a famosa descrição feita por Freud a respeito do funcionamento da estrutura psiquica; ${ }^{15}$ uma implosão que, ao final, define outras dimensōes para cada instância psíquica, engendrando um relacionamento diferente entre elas.

Em linhas gerais, talé o tipode estrutura psíquica correspondente à sociedade tecnológica atual: preponderância do imaginário e obliteração da razão em tempos de imagens em espiral. Lembre-se - por curioso ou espantoso que seja - que essa é a estrutura psíquica cujo funcionamento e desenvolvimento tem por horizonte a loucura. Numa época histórica em que imagens sem rumo e sem sentido circulam e se reciclam na rede de comunicação socialmente estabelecida, eram dese esperar consequências dessa natureza. Imagens sobre imagens refratando imagem formam um solo fértil para a alucinaçāo. Isso não quer dizer, absolutamente, que todos somos loucos - ao menos do ponto de vista clínico. Com efeito, a vida atual se desenvolve e se reajusta a uma velocidade antesjamais experienciada - ainda que as estruturas de base da sociedade permaneçam intocadas. Esse processo, uma vezoutrora desencadeado, assumiu contornos irreversiveis, sem perspectivas de minimização. Tal é a lógica do social atual: operar por operar, sem projeto nem meta racional, máquina louca solta sobre superfícies naturais e sócio-históricas.

É nessa perspectiva que, no limite, encontra-se a alucinação da estrutura psíquica, a vertigem radical na forma patológica da loucura. ${ }^{16} \mathrm{~A}$ mais leve alucinação ou a mais acabada, quer dizer, a loucura - que ronda a todos depois de um enfraquecimento gradativo do ego desde o fim da Segunda Guerra Mundial - tem estrita relação com imagens produzidas tecnologicamente $\mathrm{e}$ fomentadas socioculturalmente. Não é possivel pensar a loucura atual sem referência à socialização realizada sob fluxos incessantes de imagens. ${ }^{17}$

Reescalonem-se aqui, em síntese, os argumentos antes lançados. Por um lado, as imagens, perdendo sua ligação com a realidade, proliferam vertiginosamente, sem finalidade. Predominando no social, transformam-se em superfície de referência para a ação individual e coletiva, enquanto o real se converte em hiper-real. O hiper-real é, justamente, oreal alucinado peloefeito estético da produção tecnológica avançada. As imagens são o substrato dessa alucinação; reinam sem resistência na nova atmosfera. Por outro lado, no ritmo dessas tendências socioculturais, a estrutura psíquica se remaneja: o ego inconsciente sobrepuja o ego consciente; o imaginário se libera sem freiose prepondera em prejuizo da razão. Esse rearranjo leva a estrutura psiquica à experiência patológica da alucinação - a loucura, mais grave, figurando sempre como "catástrofe $e^{\prime \prime}$ potencial. Enlouquecimento das imagens e alucinação do real rimam com alucinação psíquica. À hipertelia do social corresponde a hipertelia mental. Nada de novidade ou mecanicismonessas afirmações: basicamente, não querem dizer senão que os individuos estão sujeitos à pressão do environment, aos múltiplos fluxos que os envolvem e os transpassam; em outras palavras, expressam a condutibilidade hoje existente entre individuos e processos socioculturais. É nessa vulnerabilidade quem sabe fatal porque inescapável - que germina a loucura.

O exposto anterior não é uma hipérbole 
teórica - se bem que é preferível o exagero à mentira. Trata-se mais de uma projeção a partir de tendências culturais do presente: os estímulose a sintomatologia da loucura social estão, de fato, dados. A teoria não deve se contentar apenas em descrever ou analisar; seu papel é, sobretudo, o de desafiar, acelerar ou antecipar. ${ }^{15}$ Num social estetizado por imagens, somos ou estamos todos alucinados a niveis leves-oque nem por issocompromete a sociabilidade; ao contrário, a impulsiona. Não obstante, como se disse, a loucura completa está no jogo e é virtual, fantasma a ser intermitentemente exorcizado. De modo que este é um desafio que se coloca a cada mortal: operar seu imaginário, inflado por incentivos sociais onipresentes, sem no entanto cair presa dele para não entregar a identidade pessoal ao roda-moinho de imagens internas descontroladas.

Certa vez, discorrendo sobre a etapa mais primordial do psiquismo humano, aquela imediatamente após o nascimento, Castoriadis $^{19}$ escreveu que o homem não é um animal racional, ao contrário do antigo refrão que se incorporou ao senso comum. Baseado na loucura total dessa etapa do desenvolvimento humano, caracterizada por Bleuler como autismo, ${ }^{20}$ Castoriadis afirmou que "o homemé um animal louco", istoé, que começa sendolouco, "eque, também por isso, torna-se ou pode tornar-se racional", ${ }^{21}$ Brilhantee provocativoargumento. Brilhante, porque inovador, e provocativo, porque rompe com toda a tradição teórica legada. Precisa, porém, sofrer reformulaçāo, apesar da cautela nele presente. Ao final do argumento, Castoriadis diz que o homem pode tornar-se racional, o que, por óbvio, nāo garantequeele se torne; ou melhor, pressupōe que ele pode também não se tornar racional, já que tal conversão é apenas uma possibilidade, não um determinismo natural indiscutível. Nessa perspectiva - e com a lembrança das formulaçōes do presente artigo -, pode-se dizer que o homem é, de fato, um ser que nasce louco, mas que, apenas potencialmente racional, no futuro talvez abdique involuntariamente de sê-lo para terminar, quem sabe, na loucura .

\section{Notas}

1 Artigo redigido em 1990, por inspiraçăo na obra de J. Baudrillard. Quase todas as partes foram posteriormente incorporadas em Trivinho, E., Estética da cultura, comunicaçẫo e pós-modernidade, São Paulo, Biblioteca da ECA/USP, 1992, Vol. II, Apèndice II. Para a presente publicação, optou-se por não se fazer nenhuma remissão bibliográfica mais atualizada em acréscimo às notas de rodapé originalmente elaboradas. N. do A., 1997.

2 Ensaísta, pesquisador do NTC - Centro de Estudos e Pesquisas em Novas Tecnologias, Comunicação e Cultura e coordenadordoGT "Comunicaçāoe Sociedade Tecnológica" da COMPÓS - Associação Nacional dos Programas de PósGraduação em Comunicaçāo.

3 Cf. Sfez, L., Critique de la communication, Paris, Éditions du Seuil, 1988, especialmente pp. 81-95.

4 Baudrillard, J., Simulacres et simulation, Paris, Éditions Galilíe, 1981, p.17.

50 termo İusầ é impreciso, mas compreensivel. Impreciso porque pode significar que só nesta fase se trata de ilusão, enquanto nas outras duas não, o que é equívoco, já que, nelas, os dados intuicionais e imaginários tomados como realidade profunda nào deixam de ser, numa perspectiva psicanalitica, também uma ilusão. E compreensivel porque, quando se acredita que algo está realmente presentee não se leva em conta sua ausência real, está-se na esfera do fantasmático, do ilusório.

6 Em Simulacres et simulation, op. cit., Baudrillard apenas pincela duas páginas (16 e 17) sobre a condição atual das imagens. Em 1987, publica um ensaio - espécie de continuação sobre o tema - em que leva sua perspectiva às últimas consequências: "Au-delà du vrai et du faux, ou le malin génie de l'image", in Cahiers Intemationaux de Sociologin, vol. 82, 1987, pp. 134-145.

7 Esse argumento pode causar certa dúvida, parecendo insinuar a cxistência, por trás dessa parafernália, de uma ação maquiavélico-manipuladora por parte de um grupo social interessado na dominação total das cabeças. O 
argumento se refere, contudo, a uma tendencia social desencadeadaespontaneamente, quesedesenvolvedeforma autônoma e em bloco por efeito da engrenagem social mesmae, poressemotivo, livre de uma direclio planificadora, seja de tipo macroeconômico, seja de tipo politico ou tecnologico.

8 Esse ponto será retomado mais a frente, ao serem abordadas as relaçies entre imagens e loucun, ocasibo em que, nos limites do percurso deste artigo, enfatizar-se 30 abo as implicaçöes politicas do fato, mas as imediatamente socioculturais e psiquicas.

9 Baudrillard, J, Sirvisces et sirolation, op. dit, p. 16.

10 Sobre o hiper-real e a simulaço, ver Baudrillard, J, "L'hypertéalisme de la simulation", in L'éckange syeblizac of is mort, Paris, Galimand, 1976, pp. 110-117; "La pretession des simulacres", in Simalacros et sieulation, op. at, pp. 9.68; e "L'atase et linertie", in Lo stratigio fateles, Editions Grascet \& Fasquelle, pp. 7.25.

\section{Baudrillard, 1, Simalactes of simalation, op. cit, p. 12}

12 Sobre esca estetizaço geral do e no social, ver Trivinho, E. 'Estetica do capital', in revista Comasicaziasupuitica, Slo Paulo, 1999, n.9, pp. 5967 .

13 Sobre a estrutura da moda como paradigma do funcionamento das sociedades modernas, vet Baudrillard, J., L'échange symboligue of la mort, op. cit. pp. 135.140.

14 Riesman, D., A maltidỉo solitíria, S5o Paulo, Perspectiva, 1971; ver especiaimente os capitulos 5, 6 e 7 da primeira parte.

15 Freud, S, 0 ego e 0 id, Imago, 1975, e Estoco de psicandilise, São Paulo, Abril Cultural, $1^{1}$ ed., 1974.

16. Alguns téricos da pos-modernidade ou da cultura findkstède, entreeles Jamesone Buoudnilard, nomeiam ofendmeno de esquizofrenia, considerada como a patologia begemonica da fase atual da sociedade secnolbgica. O assunto, porkm, carece ainda de discuscla. Ver o ensio de jameson, "Postmodernism or the cutural logic of Lse capitaism", in Nes left Revies, n' 146, jalogo/1984, pp. 53-92; ou sw versio resumida, sob otitulo"Pos-modemidadee sociedade de consumo", in revista Nowo Estads CEBRAP, SSo Pralo, jun/85, pp. $16-26$.
17 Esse é, aliass, um desafio para a teoria psicanalitica da socializaçio, que se desenvolve na Alemanha há pelo menos dez anos, sendo Alfred Lorenzer seu principal fomentador. É um desfio justamente porque tal teoria apresenta uma lacuns, entre várias, no que diz respeito aos fluxos de imugens socialmente etabelecidos e suas consequetencias culturais, politicas e psicquicas.

18 Tese de Budrilland, epprosa na ropposta que da à questio "pura que serve a teoria?; ver L'atre par lsi-minz, Paris, Editions Galike, 1967, p. 85.

19 Castoriadis, C, A irsyiniria da scindel, Rio, Paz e Tern, $192,2 \mathrm{ed}, \mathrm{p}, 342$

20 Apud Castoriadis, C, op. ot, p. 337.

21 ld ikid, p. 342 